\title{
Cryoablation-Induced Anti-Cancer Immune Reaction
}

\author{
-Immune Reaction Induced by Cryoablation
}

\author{
Shinji Osada*, Hisashi Imai, Yoshiyuki Sasaki, Itaru Yasufuku, Ryuichi Asai, Yoshihisa Tokumaru, \\ Takuji Sakuratani, Kazuhiro Yoshida
}

Surgical Oncology, Gifu University School of Medicine, Gifu, Japan.

Email: sting@gifu-u.ac.jp

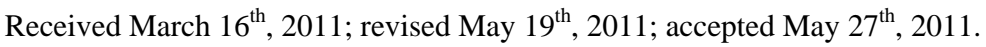

\begin{abstract}
Among the ablation procedures used against advanced liver cancer, thermal ablation therapy is widely applied, and the safety and efficacy of this technique have been well characterized. In contrast, the principle of cryosurgery is not only to control local recurrence, but also to stimulate the immune system into initiating an anti-tumor response. In recent years, we have developed a treatment method for patients with advanced liver tumors. From these experiences, repeated treatment was demonstrated to induce anti-cancer immune reaction-related factors. In the present review, mechanisms for anti-tumor immune reaction will be argued with introducing a novel strategy of a cryoablation.
\end{abstract}

Keywords: Cryoablation, Helper T Cell, Immune Reaction, Hepatoma, Ablation Therapy

\section{Introduction}

Hepatic resection has been the only curative option for patients with liver tumors. However, due to limited hepatic reserves, high surgical risk, or unfavorable tumor location, surgery is not always possible [1,2], therefore several ablative techniques, based on chemical (percutaneous ethanol injection), cold-based (cryotherapy), or heat-based (radiofrequency ablation; RFA, microwave coagulation therapy; MCT), have been developed [3]. Among these procedures, thermal ablation therapy [4,5] and cryotherapy [6] have been commonly used in world- wide, and the safety and efficacy of this technique have been well characterized. According to a recent comparative study, while similar success and complication rates were found, local recurrence is more frequent in cry- otherapy [7]. However, the principle of cryosurgery is not only to facilitate a low recurrence rate, but also due destruction of tissue intracellular antigens that are released into the circulation enable cryogenic treatment to stimulate the immune system for an anti-tumor response [6,8]. In the present report, a novel strategy with a cry- oablation-induced anti-cancer immune reaction will be introduced.

\section{Ablation Therapy for Local Cancer Progression}

Among several procedures to treat hepatic tumors, RFA is one of the most convenient and reliable regional therapies used to prolong patient survival. A worldwide study demonstrated the complication and mortality rates at $8.9 \%$ and $0.5 \%$, respectively [9], and post treatment imaging showed complete avascularity if the tumor diameter was smaller than $3 \mathrm{~cm}$ [10]. In contrast, the main effect of cryoablation is based on intra and extracellular ice formation and the intracellular ice formation causes injury of intracellular structures, membrane rupture, osmotic dehydration, anoxia and finally cell death [11]. During cryoablation the interface of the frozen/unfrozen liver can be assessed easily with intra-operative ultrasound by the appearance of an echogenic edge with posterior acoustic shadowing, and this is a major advantage of cryoablation over RFA (described later). Morbidity and mortality rates after cryosurgery were demonstrated as being higher than thermal ablation, ranging from 8 to $41 \%$ and around $20 \%$, respectively [12]. Among the complications, the phenomenon of cryoshock is responsible for the majority of all mortality. Due to this rare (1\%) but severe 
complication, cryoablation is recognized as a problematic treatment.

Larger tumor size increases the risk of complications and also of local recurrence. In a comparative study, a significantly higher local recurrence rate (38\% vs. 17\%) was reported for large tumors, diameter over $3 \mathrm{~cm}$, but not for small tumor, when RFA was compared with cryotherapy [7]. Then, RFA is now evaluated as the most favorable procedure among ablation therapies from its safety and certainty, but there are still limits in its usage due to tumor size and location [13].

\section{Significances in Immune Reaction for Cancer Progression}

Two subtypes of T-helper cells were found to have differences in cytokine secretion pattern and other functions, which indicated that Th1 and Th2 cells were important regulators of immune response. Th1 cells are hypothesized to lead the attack against intracellular pathogens such as viruses, raise the classic delayed-type hypersensitivity skin response to viral and bacterial antigens, and fight cancer cells. Th2 cells are believed to emphasize protection against extracellular pathogens such as multicellular parasites. More recently, a new subset of helper T-cells, called Th17, was reported as being related to the autoimmune diseases [14]. Th1, Th2 and Th17 subsets are produced from a non-committed population of precursor naïve $\mathrm{T}$ cells (Figure 1). As they attain maturity, Th1 cells also produce IFN-gamma, TNF-alpha, and IL-2.

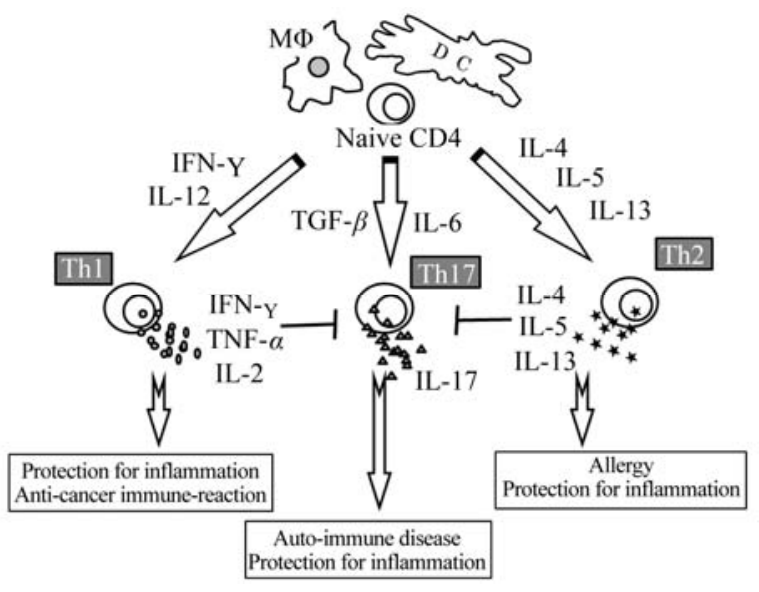

Figure 1. Schema of immune balance. Two subtypes of $T$-helper cells were found to have differences in cytokine secretion pattern and other functions, which indicated that Th1 and Th2 cells were important regulators of immune response. Th1 cells are hypothesized to lead the attack against intracellular pathogens and $\mathrm{Th} 2$ cells are believed to emphasize protection against extracellular pathogens. And more recently, a new subset of helper T-cells, called Th17, was described. Th1, Th2 and Th17 subsets are produced from a non-committed population of precursor naïve $T$ cells. The schema was identified in our previous report, [26]. Like the Th1 cells, the emergence of Th2 cells is also dependent on their cytokine environment, such as IL-4 from an APC. In addition, for Th17 cells, IL-6 or TGF-beta is important.

The development of an immune microenvironment for tumor tolerance is achieved through a variety of immune-suppressive mechanisms, and subsequently subverts the immune system away from tumor recognition and rejection $[15,16]$. During the process of immune suppression, malignant tumor progression can be associated with a general shift in Th1/Th2 immune response; Th1 cytokines are typically lower, while the Th2 marker can be higher or unchanged. Th2 reaction has a variety of suppressive effects for Th1 cytokine production and suppresses killer cells activity. In contrast, IL-12 is another cytokine that can be up-regulated by Th1 activity and subsequently, the Th1/Th2 ratio was found to be important in cervical cancer patients [17]. The macrophages associated with developing solid tumors have a phenotype that is also driven primarily by Th2 cytokines and supports a pro-tumor microenvironment [18].

\section{Novel Strategy of Cryo-Therapy}

Unresectable liver tumors were identified at our institute and selected for ultrasound echography-guided percutaneous cryosurgery (PCS) under local anesthesia with a cryoablation system (Mycom cryoneedle; Mayekawa Co. Ltd., Tokyo, Japan). The size of the ice ball was evaluated by intra-operative ultrasound, and freezing was performed for 15 minutes to make a 3-cm ice ball (Figure 2). Three freeze/thaw cycles per tumor w e r e p e r f o r m e d p e r a
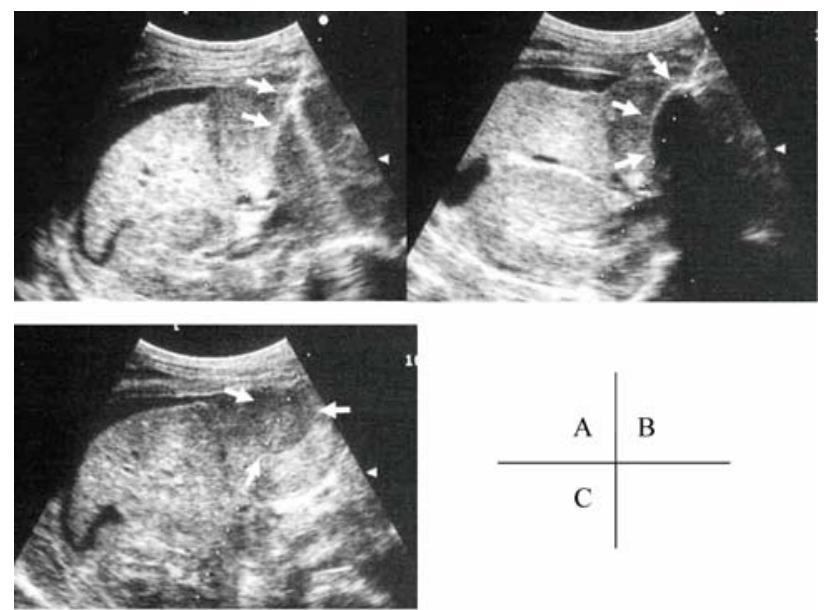

Fiure 2. Percutaneous cryosurgery. The probe of 
cryosurgery was penetrated (white arrow in A) and the size of the ice ball was evaluated (white arrow in B) by intra-operative ultrasound, and freezing was performed for 15 minutes to make a $3-\mathrm{cm}$ ice ball. The freeze area was detected after treatment (white arrow in $\mathrm{C}$ ). The findings were described in [27].

treatment. Once a week PCS was performed without any other therapy except everyday administration of polysaccharide-K (polysaccharide-Kureha; PSK) on the purpose to produce TNF-alpha [19] and to mediate Th1 dominance [20]. Evaluation of serum factors was performed before and after ablation therapy, and serum tumor markers were measured after every four treatments. Tumors were evaluated by abdominal computed tomography after eight treatments. 22 cases with liver tumor were selected for this treatment (Table 1). For all patients, PCS was performed without any serious complications. In these cases, not only were decreased levels of serum tumor markers measured, but local tumor necrosis was also observed. In addition to local changes of the treated area, tumor necrosis was identified away from the treated area in 5 cases of metastatic tumors, as described in Figure 3.

Serum AA is a major acute-phase protein released into the circulation in response to inflammation [21] and is shown to stimulate the rapid expression of TNF-alpha from cultured neutrophils [22]. Recently, TNF-alpha or IFN-gamma alone was reported to increase significantly the effect of cryo therapy [23], therefore, cryosurgeryinduced TNF-alpha expression may have mediated tumor necrosis. In fact for animal models, Th1 cells have been shown to be critical for induction of cellular immunity and eradication of the tumor mass [24]. In these particular cases (Figure 4), serum level of AA or CRP was increased after the third treatment, and the serum level of TNF-alpha was increased with keeping low of IL-10. In addition, the Th1/Th2 ratio was clearly increased with repeat treatments. To evaluate the clinical significance of these alterations in serum cytokines, pretreatment levels and maximum levels in response to therapy were compared betweenthe Immune-Reaction

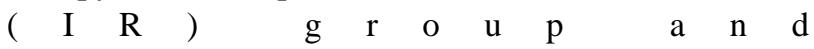

Table 1. Cryotherapy for advanced liver tumor $(n=22)$.

\begin{tabular}{lcccccc}
\hline \multirow{2}{*}{$\begin{array}{c}\text { Primary } \\
\text { organ }\end{array}$} & \multicolumn{2}{c}{ unresectable reasons } & & \multicolumn{3}{c}{ effect } \\
\cline { 2 - 5 } \cline { 5 - 6 } multiple $\begin{array}{c}\text { large or } \\
\text { invasive }\end{array}$ & $\begin{array}{c}\text { with other } \\
\text { metastasis }\end{array}$ & $\begin{array}{c}\text { no } \\
\text { response }\end{array}$ & local immune \\
stomach/ & 10 & 1 & $\begin{array}{c}\text { lung: } 6, \\
\text { bone: } 1\end{array}$ & 1 & 8 & 2 \\
duodenum & 5 & 0 & $\begin{array}{c}\text { dissemination: } 3, \\
\text { bone: } 1,\end{array}$ \\
adrenal gland: 1 & 0 & 3 & 2
\end{tabular}

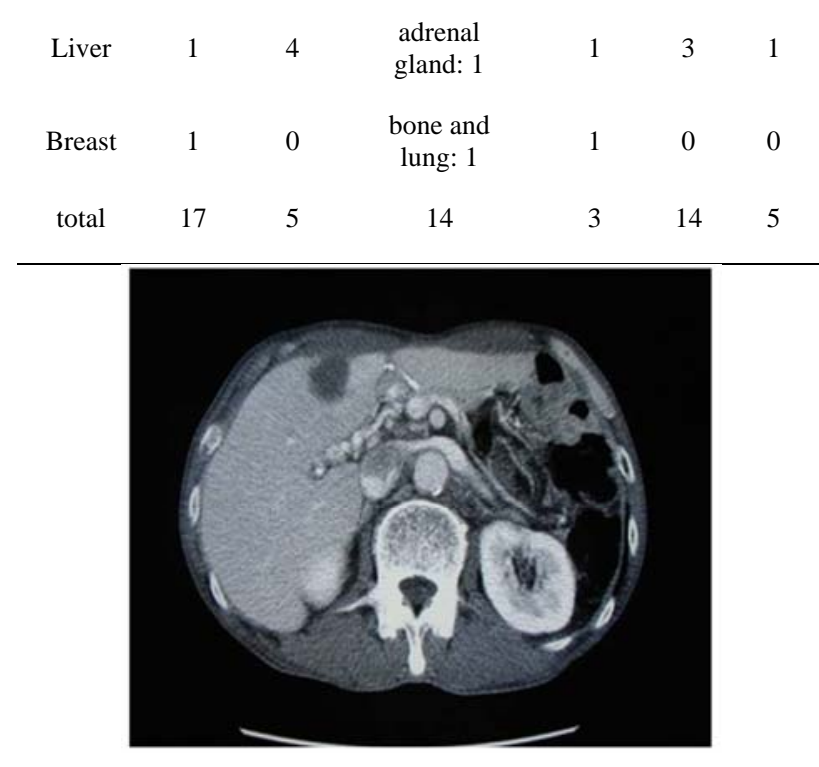

(a)

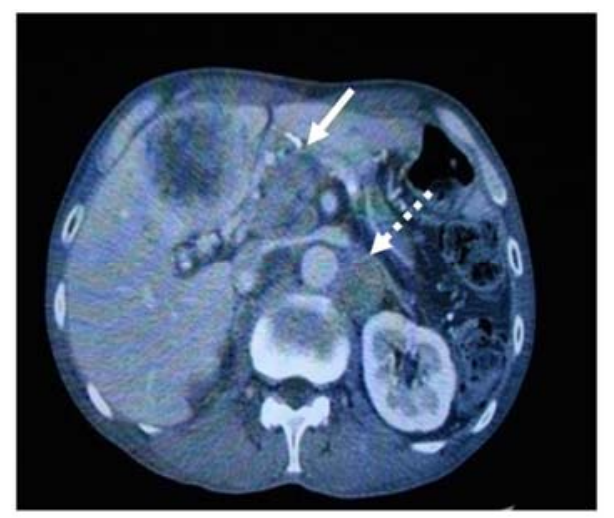

(b)

Figure 3. Benefit of cryosurgery. In the case with advanced stomach cancer, cryotherapy was performed. The cases had multiple liver metastases, lymphnode swelling around portal vein (white arrow) and peritoneal dissemination (white dot arrow) (a). After 8 times cryosurgery, not only treated liver tumors, but also dissemination mass and lymphnode swelling were diminished (b). The detail of this case was described in ref [27].

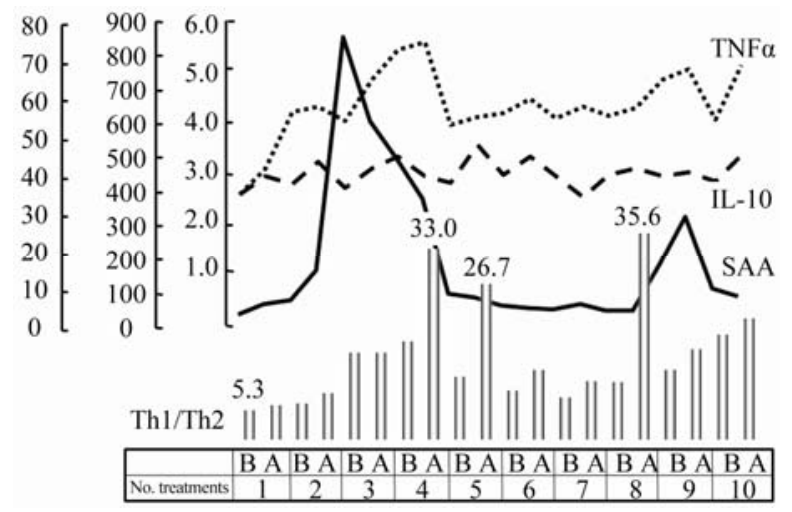


Figure 4. The changes of serum factors. Serum level of AA was increased in both the IR and LE groups after the third treatment. The serum level of TNF-alpha was increased with keeping low of $\mathrm{IL}-10$, then, the Th1/Th2 ratio was clearly increased. The number of treatments was shown in axis $x$. "b" means before and "a" means after.

local Effect (LE) group, that simple local change without any extra benefit was noted. Pretreatment levels of IL-10 in the LE group were significantly greater than in the IR group ( $p=0.0071)$, and the maximum value $(67.9 \pm 6.3$ $\mathrm{pg} / \mathrm{mL}$ ) was greater in the LE group than the IR group $(58.4 \pm 8.1 \mathrm{pg} / \mathrm{mL})$ but no significant difference was found between the two groups. In contrast, both pretreatment levels and maximum levels in response to treatment of TNF-alpha were significantly greater in the IR group than in the LE group. The maximum Th1/Th2 ratio was significantly greater in the IR group than in the LE group, despite the fact that pretreatment levels were similar between the two groups. All these details were described in a previous publication from our department [25].

We can now indicate that induction of immune responses by cryosurgery increases the usefulness of this treatment for unresectable liver tumors. Further studies will assess serum cytokine levels in order to evaluate the timing of PCS as a step-up strategy [26].

\section{Conclusions and Recommendation}

During the last decade, the development of the procedure focusing on the local control of cancer has brought highly effective instruments. On the other hand, the study of anti-cancer immune reaction has pushed new boundaries that have initiated advancements through several clinical trials. The mechanism is still uncertain, and it is unclear how the anti-cancer immune reaction is associated with cancer broken, but it is clear which factors play critical role. Cryo-surgery including the ability to release anti-cancer proteins might be emphasized to apply the immune therapy, and its possibility will lead brilliant concept, not only for the locally treated tumors, but also at the systemic level as described here, for next decade.

As a conclusion to this review, the next steps will be an exciting action to develop new approaches to blocking cancer with immune reaction theory and provide favorite outcomes for patients with advanced liver cancer.

\section{REFERENCES}

[1] C. Erce and R. W. Parks, "Interstitial Ablative Techniques for Hepatic Tumours," British Journal of Surgery, Vol. 90, No. 3, 2003, pp. 272-289. doi:10.1002/bjs.4091

[2] G. Garcea, N. Polemonivi, E. O’Leary, T. D. Lloyd, A. R.
Dennison and D. P. Berry, “Two-Stage Liver Resection and Chemotherapy for Bilobar Colorectal Liver Metastases," European Journal of Surgical Oncology, Vol. 30, No. 7, 2004, pp. 759-764. doi:10.1016/j.ejso.2004.05.009

[3] J. M. Llovet, "Updated Treatment Approach to Hepatocellular Carcinoma,” Journal of Gastroenterology, Vol. 40, No. 3, 2005, pp. 225-235. doi:10.1007/s00535-005-1566-3

[4] B. Decadt and A. K. Siriwardena, "Radiofrequency Ablation of Liver Tumours: Systematic Review,” Lancet Oncology, Vol. 5, No. 9, 2004, pp. 550-560. doi:10.1016/S1470-2045(04)01567-0

[5] E. K. Abdalla, J. N. Vauthey, L. M. Ellis, V. Ellis, R. Pollock, K. R. Broglio, et al., "Recurrence and Outcomes Following Hepatic Resection, Radiofrequency Ablation, and Combined Resection/Ablation for Colorectal Liver Metastases,” Annals of Surgery, Vol. 239, No. 6, 2004, pp. 818-825. doi:10.1097/01.sla.0000128305.90650.71

[6] S. Osada, H. Imai, K. Yawata and Y. Sugiyama, "Growth Inhibition of Unresectable Tumors Induced by Hepatic Cryoablation: Report of Two Cases," Hepatogastroenterology, Vol. 55, No. 81, 2008, pp. 231-234.

[7] R. Adam, E. J. Hagopian, M. Linhares, J. Krissat, E. Savier, D. Azoulay, et al., "A Comparison of Percutaneous Cryosurgery and Percutaneous Radiofrequency for Unresectable Hepatic Malignancies," Archives of Surgery, Vol. 137, No. 12, 2002, pp. 1332-1339.

doi:10.1001/archsurg.137.12.1332

[8] G. Poston, "Cryosurgery for Colorectal Liver Metastases,” Hepatogastroenterology, Vol. 48, No. 38, 2001, pp. 323-324.

[9] S. Mulier, P. Mulier, Y. Ni, Y. Miano, B. Dupas, G. Marchal, et al., "Complications of Radiofrequency Coagulation of Liver Tumors,” British Journal of Surgery, Vol. 89, No. 10, 2002, pp. 1206-1222. doi:10.1046/j.1365-2168.2002.02168.x

[10] T. Shibata, T. Shibata, Y. Maetani, H. Isoda and M. Hiraoka, "Radiofrequency Ablation for Small Hepatocellular Carcinoma: Prospective Comparison of Internally Cooled Electrode and Expandable Electrode," Radiology, Vol. 238, No. 1, 2006, pp. 346-353. doi:10.1148/radiol.2381041848

[11] J. Baust, A. A. Gage, H. Ma and C. M. Zhang, "Minimally Invasive Cryosurgery-Technological Advances,” Cryobiology, Vol. 34, No. 4, 1997, pp. 373-384. doi:10.1006/cryo.1997.2017

[12] C. Cha, F. T. Lee Jr., L. F. Rikkers, J. E. Niederhuber, B. T. Nguyen and D. M. Mahvi, "Rationale for the Combination of Cryoablation with Surgical Resection of Hepatic Tumors," Journal of Gastrointestinal Surgery, Vol. 5, No. 2, 2001, pp. 206-213. doi:10.1016/S1091-255X(01)80034-2

[13] M. B. Nicholl and A. J. Bilchik, "Thermal Ablation of 
Hepatic Malignancy: Useful but Still not Optimal," European Journal of Surgical Oncology, Vol. 34, No. 3, 2008, pp. 318-323. doi:10.1016/j.ejso.2007.07.203

[14] C. L. Langrish, Y. Chen, W. M. Blumenschein, J. Mattson, B. Basham, J. D. Sedgwick, et al., "IL-23 Drives a Pathogenic T Cell Population that Induces Autoimmune Inflammation," The Journal of Experimental Medicine, Vol. 201, No. 2, 2005, pp. 233-240. doi:10.1084/jem.20041257

[15] D. O. Croci, M. F. Zacarias-Fluck, M. J. Rico, P. Matar, G. A. Rabinovich and O. G. Scharovsky, "Dynamic CrossTalk between Tumor and Immune Cells in Orchestrating the Immunosuppressive Network at the Tumor Microenvironment," Cancer Immunol Immunother, Vol. 56, No. 11, 2007, pp. 1687-1700. doi:10.1007/s00262-007-0343-y

[16] G. A. Rabinovich, D. Gabrilovich, E. M. Sotomayor, "Immunosuppressive Strategies that are Mediated by Tumor Cells," Annual Review of Immunology, Vol. 25, 2007, pp. 267-296. doi:10.1146/annurev.immunol.25.022106.141609

[17] M. R. Shurin, L. Lu, P. Kalinski, A. M. Stewart-Akers and M. T. Lotze, "Th1/Th2 Balance in Cancer, Transplantation and Pregnancy," Seminars in Immunopathology, Vol. 21, No. 3, 1999, pp. 339-359. doi:10.1007/BF00812261

[18] F. Balkwill, K. A. Charles and A. Mantovani, "Smoldering and Polarized Inflammation in the Initiation and Promotion of Malignant Disease," Cancer Cell, Vol. 7, 2005, pp. 211-217. doi:10.1016/j.ccr.2005.02.013

[19] Y. Ishihara, H. Iijima and K. Matsunaga, "Contribution of Cytokines on the Suppression of Lung Metastasis," Biotherapy, Vol. 11, No. 4, 1998, pp. 267-275. doi:10.1023/A:1008070025561

[20] M. Urano, C. Tanaka, Y. Sugiyama and S. Saji, "Antitumor Effects of Residual Tumor after Cryoablation: The Combined Effect of Residual Tumor and a Protein-Bound Polysaccharide on Multiple Liver Metastases in a Murine Model,” Cryobiology, Vol. 46, No. 3, 2003, pp. 238-245. doi:10.1016/S0011-2240(03)00039-7

[21] H. Y. Rienhoff Jr, J. H. Huang, X. X. Li and W. S. Liao, "Molecular and cellular biology of Serum Amyloid A," Molecular Biology and Medicine, Vol. 7, No. 3, 1990, pp. 287-298.
[22] E. Hatanaka, C. J. Furlaneto, F. P. Ribeiro, G. M. Souza and A. Campa, "Serum Amyloid A-induced mRNA Expression and Release of Tumor Necrosis Factor-Alpha in Human Neutrophils,” Immunology Letters, Vol. 91, No. 1, 30 January 2004, pp. 33-37. doi:10.1016/j.imlet.2003.09.011

[23] B. H. Chao, X. He and J. C. Bischof, "Pre-Treatment Inflammation Induced by TNF-Alpha Augments Cryosurgical Injury on Human Prostate Cancer," Cryobiology, Vol. 49, No. 1, 2004, pp. 10-27. doi:10.1016/j.cryobiol.2004.04.005

[24] T. Nishimura, M. Nakui, M. Sato, K. Iwakabe, H. Kitamura, M. Sekimoto, et al., "The Critical Role of Th-1 Dominant Immunity in Tumor Immunology, Cancer Chemother," Pharmacology, Vol. 46, No. 1, 2000, pp. 52-61. doi:10.1007/PL00014051

[25] S. Osada, H. Imai, H. Tomita, Y. Tokyama, N. Okumura, H. Matsuhashi, et al., "Serum Cytokine Levels in Response to Hepatic Cryoablation, Journal of Surgical Oncology, Vol. 95, No. 6, 2007, pp. 491-498. doi:10.1002/jso.20712

[26] S. Osada, K. Yoshida and S. Saji, "A Novel Strategy by Cryoablation for Advanced Hepatoma," Anti-Cancer Research, Vol. 29, No. 12, 2009, pp. 5203-5210.

[27] S. Osada, K. Yawata, T. Tanahashi, N. Okumura, F. Sakashita, C. Tanaka, et al., "Report of Two Cases for Gastric Cancer Liver Metastasis Treated by Percutaneous Cryoablation Therapy with Immune Activation,” Journal of Japanese College of Surgeons, Vol. 30, No. 8, 2005, pp. 203-209. 